\title{
Open Geospatial Data for Responding to the COVID-19 Challenge
}

\author{
Maria Antonia Brovelli and Serena Coetzee
}

The period after the appearance of the SARS-CoV-2 virus has seen a flourishing of dynamic online maps and dashboards useful for communicating the spread of the disease, but not for the in-depth study of the phenomenon. The speed at which the disease is disseminated calls for rapid analysis and action. Data that is readily available, such as open data, or rapidly collected, e.g. by citizens, can make a significant contribution to modelling, understanding and containing the spread of a disease. This chapter explores open geospatial data responding to the COVID-19 challenge: What data is useful for studying the spatio-temporal spread of the virus? What is the availability of such open data? The chapter wants to answer these questions critically, also providing useful information to all those who want to support research, not only linked to this zoonosis, but more generally future epidemics and pandemics for which we should be better prepared.

\subsection{Introduction}

The globalized society of today is challenged by various emerging diseases, in many cases, zoonoses, such as the Ebola Virus Disease (EVD), bird flu, swine flu, SARS-CoV and MERS-CoV, and these are often related to climate change. Coronavirus disease (COVID-19) caused by the severe acute respiratory syndrome coronavirus 2 (SARS-CoV-2), is a classical example. COVID-19 is a communicable disease where infections are transmitted from one person to another through little droplets, emitted when someone talks or coughs. A person can be infected through direct contact with the droplets, or by touching droplets that have settled on a surface or object and touching their face afterwards [1]. COVID-19 is therefore often transmitted when people are in close contact with each other (within $1 \mathrm{~m}$ ) or in places that are frequented by many people. It also seems that certain demographics, e.g. older people, are more often severely affected by the disease.

On 11 March 2020, the World Health Organization (WHO) declared the COVID-19 epidemic a pandemic, and by October 2020, there were close to 35 million confirmed cases and more than a million deaths reported [2]. Governments have always had to respond to natural disasters and outbreaks of infectious diseases, the cause of loss of life and the devastation of both the environment and national economies.

The current viral epidemic is of colossal proportions and the rate of infection multiplies rapidly, favored by our densely populated urban centers and an interconnected global economy. Moreover this is not an isolated occurrence, as we have been experiencing similar situations with Ebola, HIV, dengue, SARS, MERS, Zika and West Nile. Researchers estimate [3] that zoonotic diseases account for $75 \%$ of all new or emerging diseases in humans. 
The recent and dramatic evolution of the COVID-19 pandemic has highlighted and accelerated some developments that were already taking place in the scientific world and in society in general. If digitization is what immediately catches the attention, a second aspect which deserves great attention, is the use of maps in the communication of information relating to the virus spread. Our daily lives have been pervaded by dashboards with maps, a key source of information about the status of the pandemic (from the beginning of the epidemic until today), ranging in scale from hotspots in cities to provinces in a country and countries on a world map.

These dashboards, however, show only simple data visualizations (e.g. number of infections per administrative area, such as country or province), which represents, even in its powerful effectiveness, only a small part of the value of geospatial information applied to health-related information. Georeferenced data, in fact, could play a crucial role in the analysis of the phenomenon itself, leading, for example, to the production of vulnerability and resilience maps, which can help, if not to eradicate the virus, at least to study its spread, evaluate appropriate containment measures for different areas, and thus reduce its impact. Generally, geospatial information constitutes potentially decisive support for offering and making accessible a multidimensional and scalable approach, necessary for the rethinking and reorganization of our entire society in a spatial perspective. Furthermore, the UN GGIM's Strategic Framework on Geospatial Information and Services for Disasters recommends that geospatial information provided by Member States and the international community "shall be openly accessible to the disaster risk management community, as appropriate" [4].

Since the problem we are facing affects the whole world, this chapter focuses on open data with global coverage. Open geospatial data with global coverage has the advantage that anyone anywhere in the world can use the data in the same way for their specific part of the world [5]. It can therefore provide a homogeneous framework to scholars and decision makers for analysing the multifaceted aspects related to the pandemic. The Open Knowledge Foundation [6] lists three key features of open data and content: 1) availability and access at a reasonable cost and in convenient and modifiable form; 2) licence that allows reuse and distribution in machine-readable form; and 3) universal participation without discrimination against fields of endeavour (e.g. commercial or non-commercial) or against persons or groups. The notion of data being "open" is not only associated with free and unrestricted access to the data, but also with transparent and inclusive consensus-based decision-making [7], [8] identified three different kinds of open geospatial data. Firstly, there is data collected by volunteers who organize themselves into communities, e.g. OpenStreetMap. Secondly, some open geospatial data is collected by authorities and published in the spirit of freedom of access to information legislation. Thirdly, open geospatial data is also collected and published by researchers to encourage reuse of the data. Another kind of data is provided by commercial organizations for humanitarian purposes, specifically in the fight against COVID-19. This chapter provides examples of these four kinds of data. Geospatial data is useful for addressing many different humanitarian and socio-economic challenges, however, in this paper, we focus only on pandemics.

This paper should not be considered to be the final milestone nor does it claim to be complete and exhaustive, but rather a path that leads to identifying what is openly available to support the activities of experts who do not belong to the geospatial domain and who need these data to contextualize and enrich their analyses with meaning. A second aspect, addressed instead at geospatial experts, is the definition of the deficiencies in the data and information that we make openly and freely available, so that anyone can acquire a direct and immediate advantage in easily using spatio-temporal products. In the next section we describe what geospatial data is useful in the case of disasters, such as the COVID-19 pandemic. Subsequently, we present and discuss several sources of relevant open geospatial data. The chapter is concluded with an assessment of the availability and suitability of open geospatial data for responding to the COVID-19 challenge. 


\subsection{What Data Is Useful for Responding to the COVID-19 Challenge?}

Epidemics and pandemics are disasters that cause significant damage to humans, physical structures, the economy or the environment. Risks associated with a disaster are reduced by following a risk management approach that identifies, assesses and reduces risks. Depending on the stage of the disaster, risks are managed by prediction, prevention, mitigation preparedness, response, recovery and rehabilitation [9]. To reduce risks associated with COVID-19, geospatial data can be used in many ways, e.g.

- to predict how the disease will spread, e.g. by identifying and analysing places or routes frequented by many people in close proximity to each other;

- to prevent the spread of the disease, e.g. by identifying vulnerable areas based on population density, demographics (age) and/or income, and protecting them;

- to mitigate the spread of the disease, e.g. by tracing people who visited the same locations as an infected person;

- to strengthen preparedness, e.g. by adjusting the number of planned surgical procedures in relation to the number of infections in a hospital's catchment area;

- to respond to the disease, e.g. by working out optimal routes for testing or awareness campaigns; and

- to monitor and communicate the spread of the disease at different scales, e.g. infections by country or province, or more fine-grained by street block, event or building and even location of an infected individual.

Table 3.1 matches different kinds of geospatial data to the different aspects of risk reduction. The remainder of this section elaborates on how these datasets can be used to identify, assess and reduce COVID-19-related risks.

TABLE 3.1

Geospatial data for risk management in disasters $(\mathrm{A}=$ Prediction, $\mathrm{B}=$ Prevention, $\mathrm{C}=$ Mitigation, $\mathrm{D}=$ Preparedness, $\mathrm{E}=$ Response, $\mathrm{F}=$ Monitor and Communication).

\begin{tabular}{l|l|l|l|l|l|l}
\hline Geospatial data & A & $\mathrm{B}$ & $\mathrm{C}$ & $\mathrm{D}$ & $\mathrm{E}$ & $\mathrm{F}$ \\
COVID-19 infections & $\mathrm{X}$ & & $\mathrm{X}$ & & $\mathrm{X}$ & $\mathrm{X}$ \\
Reference information & $\mathrm{X}$ & $\mathrm{X}$ & $\mathrm{X}$ & $\mathrm{X}$ & $\mathrm{X}$ & $\mathrm{X}$ \\
Places frequented by many people & $\mathrm{X}$ & $\mathrm{X}$ & $\mathrm{X}$ & $\mathrm{X}$ & & $\mathrm{X}$ \\
Travel networks and mobility & $\mathrm{X}$ & $\mathrm{X}$ & $\mathrm{X}$ & $\mathrm{X}$ & & $\mathrm{X}$ \\
Land cover & $\mathrm{X}$ & $\mathrm{X}$ & & $\mathrm{X}$ & & \\
Address data & $\mathrm{X}$ & & $\mathrm{X}$ & & $\mathrm{X}$ & \\
Demographic data & $\mathrm{X}$ & $\mathrm{X}$ & & $\mathrm{X}$ & $\mathrm{X}$ & \\
Air pollution & $\mathrm{X}$ & $\mathrm{X}$ & & $\mathrm{X}$ & & \\
Water sources & $\mathrm{X}$ & $\mathrm{X}$ & $\mathrm{X}$ & $\mathrm{X}$ & $\mathrm{X}$ & \\
Health facilities & & & & $\mathrm{X}$ & $\mathrm{X}$ & $\mathrm{X}$ \\
\hline
\end{tabular}

Based on knowledge at the time of writing, the COVID-19 disease is mainly transmitted through close physical contact and respiratory droplets. Contamination happens either through direct contact with respiratory droplets or through droplets that have settled on a surface or object. Transmission happens when a contaminated hand touches the mouth, nose or eyes [1]. Therefore, places frequented by many people or where people are in close proximity to each other present a higher risk of transmissions. Because transmission happens through respiratory droplets emitted by people, tracking the locations visited by contaminated people and closing them for a period of time can help to contain the spread. 
Geospatial information about locations and routes that are frequented by many people is of specific relevance when studying COVID-19. Examples are networks of public transport and travel by air; capacity and occupation of places or buildings where people may gather in large groups, such as socio-sanitary and social structures, educational institutions, recreational, cultural, sporting structures, penitentiary institutions, structures of social marginality, accommodation in general; places characterised by large concentrations of people, e.g. related to agriculture (e.g. markets), commerce (e.g. shopping centres) and industry (e.g. factories); and in poorer communities, communal toilets and water taps may pose a risk to COVID-19 transmission.

It has been observed that the risk of zoonosis, i.e. a pathogen such as a virus or a parasite moving from animal to humans, is higher when there are significant ecological changes in an area [10]. In such cases, humans may come into close contact with animals that previously lived far away from any human activity. Land cover datasets provide information about such ecological changes and can help with identifying areas at risk of zoonosis.

In order to study and understand the actual spread of the disease, location-based information about the infected people and the places they visited is required. Information about such locations is often provided in the form of a residential address that has to be converted into coordinates through geocoding based on geo-referenced address data. However, to protect the personal information of individuals, the information is usually published in an aggregated form, e.g. by administrative or statistical boundary. Administrative areas, place names and address data are also relevant when determining and reporting who may be affected by the predicted spread of the disease.

Older people (above 60 years) and those with underlying medical conditions, such as cardiovascular disease, chronic respiratory disease, diabetes and cancer, are at a higher risk of complications or the disease being fatal [1]. Therefore locations where these people receive care, such as old age homes, hospitals and long term care facilities, need special protection. The nature of the household may also present a vulnerability. When different generations live together in the same household, it may be difficult to isolate the older generation from the rest of the household. Similarly, when many people share the same room or ablutions, e.g. in dormitories or large families, physical distancing measures to avoid contamination may be difficult. To identify vulnerable areas that need protection, demographic and population data play an important role, including geospatial data about the socio-economic status, age, health conditions, lifestyle, household size and population density.

Another vulnerable part of the population lives in slums and informal settlements, or is displaced and lives in camps and camp-like settings. Such communities are often neglected or stigmatized and without access to health care services that are otherwise available to the general population. Satellite imagery can be used to detect such settlements, if they are not yet reflected in datasets of authorities. Satellite imagery and data contributed by volunteers, e.g. through the OpenStreetMap ecosystem, is also essential for understanding these settlements so that control measures and interventions amenable to the spatial characteristics of the settlement can be planned and implemented, e.g. routes for community health workers involved in testing campaigns or access points for delivering food parcels.

Frequent and thorough hand hygiene is one of the most important measures to prevent the spread of COVID-19 [11]. Unfortunately, a large part of the world's population does not have access to a basic hand washing facility with soap and water in their home. In 2017, three billion people were without such a facility [12]. These people are vulnerable to the COVID-19 disease and any information about access to safe drinking water can help to identify those without such access.

Other examples of vulnerabilities are non-communicable diseases, such as hypertension, diabetes and chronic respiratory disease, e.g. linked to air pollution [13]. Environmental datasets about the concentration of air pollution and data about the prevalence and spatial distribution of non-communicable diseases can help with identifying parts of the population vulnerable to COVID-19.

In the WHO's interim guidance on critical, readiness and response actions, objectives for controlling and slowing down COVID-19 infections include rapidly finding (e.g. through testing) and isolating cases, and tracing their contacts; suppressing community infections by implementing control measures at locations at risk; and reducing mortality by ensuring continuity of essential social and health services [14]. Geo-referenced address data can help with locating cases and their contacts, e.g. through geocoding, while other geospatial data layers identify locations at risk (see 
above) where control measures have to be implemented. Spatial accessibility and capacity of health services in response to the disease can be assessed with geospatial data about hospital locations, their available equipment (e.g. intensive care units and ventilators) and occupation (e.g. availability of beds in general wards). Additionally, the locations and capacity of places collecting and treating medical and hazardous waste, e.g. infected masks, gloves and other personal protection equipment (PPE), can be identified and assessed.

Citizen science projects involving geospatial data present the opportunity to strengthen preparedness and responses. For example, volunteers can contribute data that provides geospatial reference, such as the road network, landmarks and health facilities. They can further enhance this data by adding opening times of health facilities, such as pharmacies, in their local communities.

In summary, location-based data that helps to answer the following questions is useful for responding to the COVID-19 challenge:

- Where are locations with high risk of transmission?

- Where are the vulnerable people?

- Where are the infected people, and where were they in the past few weeks?

- Where are the healthcare facilities that can support infected people?

To communicate the answers to these questions, a base map is required for context and orientation. The base map shows reference information, such as landmarks, place names, transportation routes, administrative areas or an aerial photo as backdrop. These help the map reader with determining and orienting the location of the map. Depending on the purpose of the map, the reference information may differ; in some cases satellite imagery or aerial photography is used.

\subsection{What is the Availability of such Open Data With Global Coverage?}

In this section we present and discuss several sources of open geospatial data with global coverage identified as useful for responding to the COVID-19 challenge in the previous section. The link in the Annex lists URLs for datasets discussed in this section, together with the formats and licenses in which they are published.

\subsubsection{COVID-19 Infections}

The first datasets we have to deal with are those related to the virus evolution in time and space. The global coverage of available open data is good enough because almost all countries are included but the resolution is very poor. Data are generally available per country and not with any more detail. The first and main source of information is the dataset made freely available for non-profit public health, educational, and academic research purposes in a GitHub repository [15] by the Center for Systems Science and Engineering (CSSE) at the Johns Hopkins University (JHU). Data sources are many and various, mainly the different national agencies, and the great value of the JHU dataset is that, after their manual and automatic pre-processing, data are available in a standard format.

The folders contain daily case reports of confirmed cases $(C)$, deaths $(D)$, recovered cases $(R)$ and active cases (A), where $\mathrm{A}=\mathrm{C}-\mathrm{R}-\mathrm{D}$.

Moreover, some computed indexes are also available, such as the Case Fatality Ratio (CFR), which allows immediate comparison between data from different countries, as well as the creation of thematic maps , e.g. choropleth, as it is the relative value of confirmed cases per 100,000 persons.

For the sake of comparing data between different countries, the European Centre for Disease Prevention and Control [16] provides new total cases and deaths day by day, as well as the 
population count in 2018. This data is ready for studying differences in the evolution of the virus because curves, e.g. by shifting it in such a way that all sets have the same starting outbreak point (for instance, corresponding to a certain percentage of the affected population).

The United Nations Statistics Division, in partnership with Esri, makes the layers of JHU available in various formats, including KML, GeoJSON and shapefile. The data is also accessible through an API and Geoservices [2].

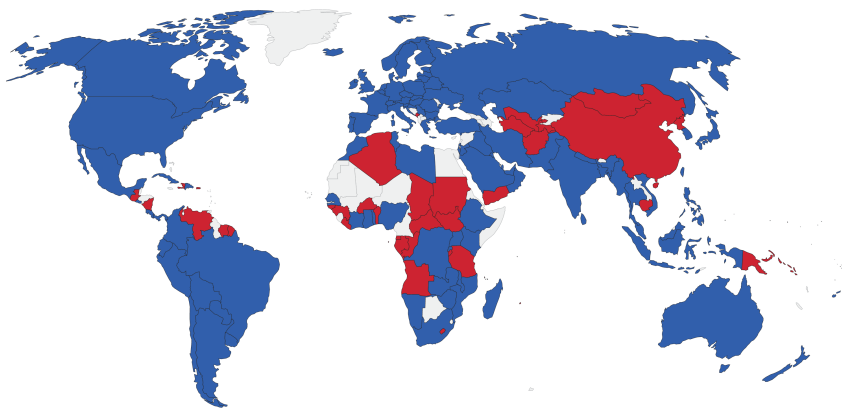

Included in dataset

\section{FIGURE 3.1}

Countries included in the Our World in Data COVID-19 Testing Dataset (Source: Official data collated by Our World in Data [17])

Finally, information about COVID-19 testing, collected by Our World in Data [18], is published as open data. The testing dataset is updated around twice a week. The dataset includes, for the countries visible in Figure 3.1, a detailed description of how the country's data is collected [17]. Some ancillary information, such as hand washing facilities (from the United Nations Statistics Division) and hospital beds per 1,000 people (from many documented sources) are also available.

\subsubsection{Reference Information}

When information is communicated via a map, reference information provides context and orientation. For a thematic map, reference is usually provided by a small set of layers, e.g. country or state boundaries and their names. Depending on the scale, more (e.g. thematic map of a city) or less (e.g. thematic map of the world) reference information can be provided. Other types of maps, e.g. one that displays locations of health care services in a specific city or suburb requires much more reference information, including such features as addresses, streets, public transportation and landmarks. In some cases, an aerial photo or satellite image of the area can be useful. While data discussed in other subsections can also be used as reference information on maps (e.g. the travel network in 3.3.4), in this section we focus on base maps, imagery, place names and administrative areas.

\subsubsection{Base Maps}

OpenStreetMap is a crowdsourced dataset to which a global community of mappers contributes geospatial information and maintains it. OpenStreetMap was inspired by Wikipedia and started in the UK in 2004 as an alternative to proprietary map data with restrictions on the availability and use of data. It is maintained through an ecosystem of software, servers, tools, users, and contributors 
[8]. In many parts of the world, the quality, and specifically the completeness, of OpenStreetMap data is as good as that of authoritative datasets, if not better [19], and if the quality is not good enough, the OpenStreetMap ecosystem makes it very simple for anyone to add or improve the data. In this context, OpenStreetMap has been used very successfully during disasters and humanitarian initiatives, including the COVID-19 pandemic, where volunteers added data remotely in areas where data are scarce or non-existent [20]. A large number of mapping tasks, e.g. including Peru and Botswana, were published on the task manager of the Humanitarian OpenStreetMap Team (HOT) during the COVID-19 pandemic. Volunteers from all over the world contributed map data that could subsequently be used by health workers.

The OpenStreetMap ecosystem presents another advantage: a range of tools are available for collection, maintenance, processing and visualization of data. OpenStreetMap is widely used as a basemap in COVID-19 dashboards (see e.g. [21], [22], [23], [24]) and also on websites that show emerging hotspots of infections (e.g. [25], [26]). Many of these sites were built with one of the tools in the OpenStreetMap ecosystem, such as mapbox and Leaflet.

Wikimapia is another example of a crowdsourced map with global coverage, where anyone can add geospatial features and annotate them. It was started in 2006 by two Russian Internet entrepreneurs, inspired by Wikipedia. Wikimapia is open data, but it is derived largely from aerial imagery provided by Google Maps. Copyright related to such derived data is sometimes unclear and dependent on the area of jurisdiction (country or region). Some owners of aerial photography provide licenses for the use of the data but retain the exclusive right to derive geospatial data from it. While Google has not initiated any legal court battles over this, their terms and conditions prohibit derivations without a license from Google [27].

Natural Earth is maintained by a community of volunteers, supported by the North American Cartographic Information Society. In contrast to the previous two datasets, it also includes raster data (e.g. for shaded relief and bathymetry), and some layers specifically useful for small scale maps, e.g. graticules and geographic lines (polar circles, tropical circles, the equator and the International Date Line). The data can be downloaded at scales of 1:10 m, 1:50 m, and 1:110 million, which is not as detailed as OpenStreetMap and Wikimapia, but nevertheless suitable for maps of the world or specific countries and regions. At the time of writing, the latest version (v4.1.0) was announced in 2018 , therefore the data is also not as recent as the previous two datasets, however, at the available scales, the data is not likely to change frequently [28].

\subsubsection{Imagery}

A rich dataset of free and open satellite imagery, with different spatial and temporal resolutions and useful for studying different parameters, is available. Specific licenses depend on the agencies which are providing the data. Formats also depend on the satellites and, in some cases, images are available in more than one format. The best way for finding imagery is to browse portals (see relevant examples in Table 3.2), which make this satellite imagery available and often also tools for their basic processing [29].

TABLE 3.2

Portals with access to free and open satellite data

\begin{tabular}{l|l} 
Portal & URL \\
USGS Earth Explorer & https://earthexplorer.usgs.gov \\
LANDVIEWER & https://eos.com/landviewer/ \\
COPERNICUS OPEN ACCESS HUB & https://scihub.copernicus.eu \\
SENTINEL HUB & http://apps.sentinel-hub.com/eo-browser, http: \\
& //apps.sentinel-hub.com/sentinel-playground \\
NASA EARTHDATA SEARCH & https://search.earthdata.nasa.gov \\
REMOTE PIXEL & https://search.remotepixel.ca \\
INPE IMAGE CATALOG & http://www.dgi.inpe.br/catalogo \\
\hline
\end{tabular}

Another interesting portal is that of OpenAerialMap [30], where one can find, apart from some openly licensed satellite imagery, also imagery from unmanned aerial vehicles (UAVs). All imagery 
is made available through the Humanitarian OpenStreetMap Team's Open Imagery Network (OIN) Node. The images are available for tracing in OpenStreetMap.

\subsubsection{Place Names}

GeoNames is a global database of more than 25 million names for 11 million geographical features, classified into nine categories (e.g. administrative areas, water features, parks, etc.), and further classified into 645 different feature codes. At the time of writing, GeoNames included 4.8 million populated places. GeoNames integrates data from various sources. The quality of the data depends on the source that contributed the data, therefore a wiki interface allows users to improve the quality by editing, correcting or adding new names through a wiki interface.

The GEOnet Names Server (GNS) is the official repository of standard spellings of geographic names outside the United States, sanctioned by the United States Board on Geographic Names (US BGN). At the time of writing, it included 12 million names for 7 million features, each feature described by its feature class, location, administrative division, and quality. The data can be downloaded as text files (per country or feature class or the entire dataset), or accessed through web services [31]. For a global dataset, place names in the US and Antarctica can be added by downloading them from the US BGN geographic names information system [32].

In the above sources features are represented by a point. These are useful as labels on maps or to search for a place. However, sometimes boundaries (polygons) are needed. Quattroshapes is a gazetteer of non-overlapping polygons, distinguishing it from gazetteers with simple point geometries. The gazetteer is based on data from GeoNames, Yahoo GeoPlanet, Flickr geotagged photos and EuroGeoGraphics [33].

\subsubsection{Administrative Areas}

Thematic maps show information about a specific theme, e.g. about COVID-19 infections. Such information is often displayed per administrative area, such as country, state, province, city, municipality, suburb or ward.

The World Bank publishes a dataset with administrative boundaries approved by the organization. The dataset includes international (country) boundaries, disputed areas, coastlines and lakes [34]. Sub-national boundaries for individual countries can be downloaded from the Humanitarian Data Exchange of the United Nations Office for the Coordination of Humanitarian Affairs (OCHA) [35].

For lower level administrative boundaries, GADM, a global dataset of administrative areas at all levels of sub-division, is available [36]. The GADM project sourced data for many countries from their national governments, from NGOs, and/or from maps and lists of names available on the Internet (e.g. from Wikipedia) [37]. This dataset is convenient to use because it is available as a single global layer, however, care should be taken, as it is not necessarily based on the latest authoritative sources (the website provides limited information).

Administrative boundaries are also included in some other datasets, such as Natural Earth and OpenStreetMap. Once again, care should be taken because these are not necessarily based on authoritative sources.

\subsubsection{Places Frequented by many People}

Because COVID-19 is mainly transmitted through close physical contact and respiratory droplets, places frequented by many people or where people are in close proximity to each other present a higher risk of transmissions. A first indicator for areas containing places frequented by many people would be data about settlement and population density. Locations of refugee camps are another way of identifying places frequented by many people. They are typically densely populated and have been identified to be COVID-19 vulnerable by the WHO. A list of refugee camps from 2014 is available in [38]. An online world map, as well as maps and statistics published as PDFs, are available on the UNHCR operational portal for refugee situations [39]. However, despite our extensive searches, including the UNHCR portal, we could not find downloadable location-based data about refugee camps. 
Once areas with high settlement or population densities have been identified, data about specific places frequented by many people in these areas are useful for risk management at a larger scale. A plethora of different kinds of places could be relevant, ranging from supermarkets, restaurants, shopping centres to fitness centres, stations, schools and universities. On maps and in geospatial data, these are often referred to as points of interest.

While completeness of data in different countries and regions varies, OpenStreetMap includes an extensive set of points of interest (close to 33 million points), each identified with the "amenity" tag. At the time of writing, there were at least 71 different kinds of amenities in seven different categories: sustenance, education, transportation, financial, healthcare, entertainment, arts \& culture, and others. Several tools and scripts are available for extracting points of interest from the OpenStreetMap dataset [40]. Wikimapia is another crowdsourced geospatial dataset. At the time of writing it included close to 24 million points of interest in 94 different categories [41].

Points of interest datasets are widely used, not only on maps, but also for a wide range of location-based services, e.g. for reviewing or recommending points of interest. Studies specifically about the quality of points of interest in OpenStreetMap and Wikimapia have not been conducted at a global scale; they have however been included in studies about the quality of OpenStreetMap generally. Barriers for assessing the quality of points of interest generally include the fact that no reference datasets exist against which one can compare them (apart from comparing OpenStreetMap to Wikimapia), they cannot be assessed against satellite imagery, which is possible for many other kinds of features (e.g. building and roads), and ground truthing at a global scale is just too expensive. Nevertheless, OpenStreetMap and Wikimapia are often the only available open datasets for points of interest and therefore useful. The quality of individual classes of points of interest, for which reference datasets exist, can however be assessed e.g. for transportation or health facilities. See also sections 3.3.4 and 3.3.10 in this regard.

\subsubsection{Travel Networks and Mobility}

The official global reference dataset for transport networks is Global Roads, version 1 (gROADSv1), based on the combination of the available, and topologically correct, road data at national level. The common data model is that of the United Nations Spatial Data Infrastructure Service (UNSDI-T). The data were collected, harmonized and homogenized over an extensive period of time, spanning a few decades. This means that updating the data and spatial accuracy may vary greatly from country to country [42].

The second dataset of interest is OpenStreetMap. The project was initiated specifically for collecting data about streets, not only their geometry, but also any features related to transportation networks. The main features related to travel networks are: arialways, aeroways, highways, public transport, railways, routes and waterways. The many different typologies and the many attributes used for the description of the features make this dataset an invaluable source of detailed information [43].

Despite its heterogeneity in spatial and semantic distribution, the dataset is rich and accurate in many developed regions [19], [44], [45] and richer than gROADSv1 in (at least some) developing countries [46] compared OpenStreetMap against gROADSv1 in Tanzania, Uganda and Kenya, finding that the former shows less roads in the ratio of 5.6, 6.5 and 2.5 respectively. Moreover, the mean spatial accuracy is $35 \mathrm{~m}$ for OpenStreetMap and $600 \mathrm{~m}$ for gROADSv1.

About mobility, recently, data was made available by Google (open data) and Facebook (upon agreement). Google trends [18] aim to provide insight into what has changed in response to policies aimed at combating COVID-19. They are based on anonymized data collected by apps such as Google Maps when the user turns on the Location History setting (which is off by default). Data are not absolute values, but rather the changes in time referred to a baseline day, which is the median value from the 5 -week period between 3 January and 6 February 2020. Data are aggregated per day (starting from 16 February) and per country (where available), and represent the change in the number of visitors to specific types of location: grocery stores, pharmacies, parks, train stations, 
retail, recreation, and workplaces; and the duration in case of the residential category. Data per region (second administrative level) is available at [47].

In response to the COVID-19 pandemic, Facebook launched an initiative within Facebook Data for Good [48], and made available, for researchers and non-profit operators who have signed data license agreements, different typologies of maps and geospatial data: co-location maps, trends and staying at home maps, movement maps, network coverage maps and maps of the Social Connectedness Index, which measures the strength of connectedness between two geographic areas as measured by Facebook friendship ties.

Data are provided by Facebook as CSV files upon request, starting from the day of the request, on a grid that follows the Bing Tile System [49]. For the spatial resolution, in principle, the smallest allowed size guaranteeing privacy protections is Bing Tile Level 16, which is equivalent to roughly $600 \mathrm{~m}$ near the equator, but the resolution of the requested dataset is computed on the base of the time needed for its periodical update. The calculation of the movement data is much heavier, from the computational point of view (cross matrix of calculations between all the panes) than the population count, and this is the reason why the spatial resolution of the movement datasets is coarser than that of the population density (see later section 3.3.7) and depends strongly on the size of the area of interest. As examples, in the case of Italy and the Lombardy region within Italy, pixel sizes are respectively about $7.5 \mathrm{~km}$ (Bing Tile Level $4-9.8 \mathrm{~km}$ at the equator) and 3.5 $\mathrm{km}$ (Bing Tile Level $5-4.9 \mathrm{~km}$ at the equator). Lombardy covers approximately $8 \%$ of the whole Italian territory, with $16.7 \%$ of its population (mean density equal to 422 inhabitants $/ \mathrm{km}^{2}$ ). The temporal resolution is 8 hours.

Apart from the above, two datasets are available to everyone: the "Change in Movement", which compares the movement of people with respect to a baseline period; and the "Stay Put", which provides information on the fraction of the population that appears to stay within a small area surrounding their home for an entire day. The Movement Range data is available as a CSV file only for some countries. All the maps are based on data collected from Facebook users.

\subsubsection{Global High-resolution Land Cover Maps}

The anthropization of the environment (deforestation, habitat degradation and fragmentation, intensification of agriculture and climate change) facilitates the passage of pathogens from animals to humans. To study the extent of these effects, the basic maps to start from are land cover maps. Thanks to the availability of open satellite images in ever increasing resolution, in recent years we have witnessed the creation of various maps that can be a valuable tools for researchers from different environmental disciplines. Some of these maps are multiclass, such as GlobeLand30 and FROM-GLC. Others represent specific elements of interest, such as urbanized areas (Global Urban Footprint and Global Human Settlement Layer), water resources (Global Surface Water) and forested areas (Forest/Non-Forest map and Global forest cover gain/loss). Some characteristics of the land cover maps can be seen in Table 3.3.

Apart from these datasets, as for the other features of interest, OpenStreetMap can be a good source of data. Specifically, in OpenStreetMap the detail of land use is reported. Therefore, from the point of view of knowledge about an area, the information is also richer than basic land cover data, even if the limitation is that it is not homogeneously distributed across the globe, because the amount of data in an area depends on the activity and contributions of volunteers in that area.

\subsubsection{Address Data}

Addresses are essential for locating infected cases, to trace contacts after someone tests positive, to accurately identify and respond to emerging clusters of COVID-19, and to determine households at risk as a result of these clusters. Addresses are typically maintained by local authorities [50], however, a global uniform open dataset facilitates the development of tools that can leverage economies of scale. The Universal Postal Union (UPU) [51] supports countries to develop and improve their addressing systems. The aim is to improve the coverage of addressing infrastructures globally. However, the UPU does not publish open address data. 
TABLE 3.3

Global high-resolution land cover maps

\begin{tabular}{|c|c|c|c|}
\hline & $\operatorname{Res}(\mathbf{m})$ & Year $(s)$ & Producer \\
\hline GlobeLand30 (GL30) & 30 & $\begin{array}{l}2000,2010 \\
2020\end{array}$ & National Geomatics Center of China \\
\hline FROM-GLC & 30 & $\begin{array}{l}2010,2015 \\
2017\end{array}$ & Tsinghua University \\
\hline Global Urban Footprint & 12 & 2011 & German Aerospace Center (DLR) \\
\hline $\begin{array}{l}\text { Global Human Settlement Layer (GHS } \\
\text { BUILT-UP GRID S1) }\end{array}$ & 20 & 2016 & Joint Research Center (JRC) \\
\hline Global Surface Water & 30 & $\begin{array}{l}\text { 1984-2018, } \\
\text { every year }\end{array}$ & Joint Research Center (JRC) \\
\hline Forest/Non-Forest map & 25 & $\begin{array}{l}2007-2010, \\
2015-2017 \\
\text { every year }\end{array}$ & $\begin{array}{l}\text { Japan Aerospace } \quad \text { Exploration } \\
\text { Agency (JAXA) }\end{array}$ \\
\hline Global forest cover gain & 30 & $\begin{array}{l}2000-2012, \\
\text { (one map for } \\
\text { the whole } \\
\text { period) }\end{array}$ & $\begin{array}{l}\text { Hansen/UMD/Google/ } \\
\text { USGS/NASA }\end{array}$ \\
\hline Global forest cover loss & 30 & $\begin{array}{l}\text { 2001-2019, } \\
\text { every year }\end{array}$ & $\begin{array}{l}\text { Hansen/UMD/Google/ } \\
\text { USGS/NASA }\end{array}$ \\
\hline
\end{tabular}

An alternative is the OpenAddresses.io initiative [52]. Data is collected from authorities all over the world, integrated into a uniform data model, and made available for downloads. Data sources can be added or improved through a GitHub site. In 2020, OpenAddresses consisted of more than 475 million addresses integrated from thousands of sources from all over the world. Figure 3.2 shows the coverage on 4 October 2020.

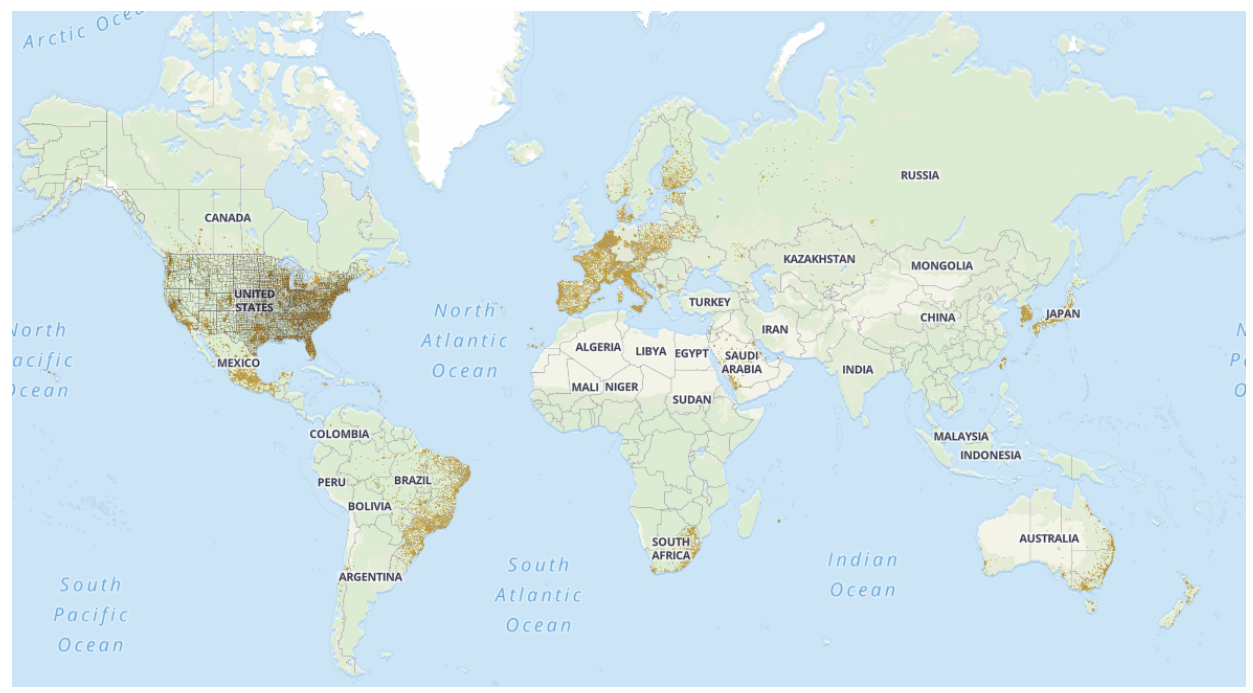

\section{FIGURE 3.2}

Global coverage of OpenAddresses.io on 4 October 2020 [52]

Addresses in OpenAddresses.io follow a rather restrictive data model, essentially comprising a number, street, city, postcode, district, region, and an additional attribute called "unit" for uniquely identifying different units at the same address. Each address has a unique identifier and a coordinate associated with it. One can specify the type (e.g. industrial or residential) of the address and add notes. The data model does not specifically cater for local variations, such as addresses without street names or addresses requiring both a suburb and a city or municipality name [53]. Following an international data model, such as that specified in ISO 19160-1 [54], would resolve 
this. Apart from improving issues that arise when address data is converted from source model to the OpenAddresses.io model, there are no quality checks on the address data per se, as this is the responsibility of the authority from where the data is sourced.

Addresses in OpenStreetMap are tagged with "addr:housenumber". Addresses can be a feature on their own or they are associated with a building, site or other area. In some parts of the world, address ranges are available, i.e. a line (called "way" in OpenStreetMap) tagged as "addr:interpolation" runs parallel to the street. The start and end nodes of the line are tagged with the numbers of the addresses closest to them. Address ranges do not provide individual address records, but in the absence of other address data, such ranges are very useful for routing and geocoding because the location of addresses with numbers between those at the start and end nodes can be interpolated along the line. Early in October 2020, there were just over 106 million "addr:housenumber" tags in OpenStreetMap, and close to 100 million fewer "addr:street" tags [55]. Challenges with the way in which addresses are represented in OpenStreetMap have been noted and improvements have been proposed [56]. Address data can be extracted and downloaded in the same way as any other OpenStreetMap data.

A single source of uniform address data across the world makes it possible to develop geocoding tools and services that can be used anywhere in the world for locating infected patients and their contacts. For example, a geocoding service based on OpenStreetMap data is available at https://nominatim.openstreetmap.org. Some geocoding services, such as https://geocode. earth/sources, are based on multiples data sources including OpenStreetMap and OpenAddresses.

\subsubsection{Demographic Data}

Demographics is a huge field, encompassing characteristics of the population in terms of population density, age, gender, socio-economic, health conditions, presence of vulnerable population, lifestyle, etc. General data sources, to be considered for our purposes, include open data published by the World Bank [57] and the Organisation for Economic Co-operation and Development (OECD) [58]. In the former, data are available in various formats, with various temporal extensions, and there is a special section related to COVID-19. The latter contains data of OECD countries and some non-OECD economies. The temporal coverage consists of different years, depending on the specific parameter under consideration; the most recent year is generally 2018 .

Among the various characteristics of the population, the population age and its density were considered by the authors as examples, because of their importance with respect to COVID-19: the older population has more severe symptoms and density of the population is inversely related with social or physical distancing required to combat the virus.

About age, classes for population ranges 0-14 [59]; 15-64 [60]; and above 65 [61], considering male, female, total, absolute number and percentage per country were estimated by the World Bank based on the World Bank's total population and age/sex distributions of the United Nations Population Division's World Population Prospects: The 2019 Revision [62], [63]. The temporal coverage is from 1960 to 2018. If interested in the population with a certain age or within a certain age interval, these data can be found, for OECD countries and some non OECD economies, in the OECD's statistics. The temporal coverage is again from 1960 to 2018.

For population density, three global high resolution global datasets are available. The Gridded Population of the World, most recent version is GPWv4.11 [64], is a set of raster layers with the estimates of the count and density of people per 30 arc-second (around $1 \mathrm{~km}$ ) grid cell for each of the five years: 2000, 2005, 2010, 2015 and 2020, consistent with national censuses and population registers. All estimates of population counts and population density have also been nationally adjusted to population totals from the United Nation Population Division's World Population Prospects: The 2015 Revision [65]. Data is downloadable in ASCII (text), GeoTiff and netCDF format. In addition, rasters are available for basic demographic characteristics (age and sex), geographic characteristics (land and water areas) and data quality indicators [64].

An interesting dataset, even if limited for now to 169 countries, is provided by CIESIN and the Connectivity Lab at Facebook [66]. The name of this dataset, computed for 2015, is the High Resolution Settlement Layer (HRSL) and its resolution is of 1 arc-second (approximately $30 \mathrm{~m}$ ). The population estimates are based on recent census data and high-resolution $(0.5 \mathrm{~m})$ satellite imagery from DigitalGlobe. 
The second global dataset is GHS_POP Global population grids at epochs 1975, 1990, 2000, 2015 and with resolution of $250 \mathrm{~m}, 1 \mathrm{~km}, 9$ arcsec, 30 arcsec.

The third source of data is WorldPop [67]. Different datasets are provided, based on different methodologies [68]. Data can be downloaded per country at a resolution of 3 and 30 arc-seconds (approximately $100 \mathrm{~m}$ and $1 \mathrm{~km}$ at the equator, respectively).

The last dataset worth mentioning is a dynamic one and is available within the already mentioned initiative of Facebook Data for Good. Data about population density (more precisely, Facebook user density) has a temporal resolution of 8 hours and a spatial resolution varying on the region of interest, following the same rule seen in section 3.3.4 for mobility data. In the case of population density, the resolution is better because the time of computation for the updated data is lower. Considering the previous examples, the pixel size is that of a tile at Bing Tile Level 5 for Italy (around $3.5 \mathrm{~km}$ at the equator) and of Bing Tile Level 7 for Lombardy (around $1.2 \mathrm{~km}$ at the equator).

\subsubsection{Concentration of Air Pollutants}

Air pollution is one of the world's largest health and environmental problems. Even if there has been a general decrease in air pollution in rich countries in comparison to the threatening concentration of some decades ago, localised high values still remain in some areas, and in middle-income countries the death rates due to air pollution are the highest. Moreover, persistent exposure to air pollution weakens the respiratory system, creating a continuous irritation. There are two different typologies of pollution: outdoor and indoor (household).

Global data about outdoor air pollution are generally available per country. An example is the 1990-2016 series of concentrations of particulate matter with a size of less than $2.5 \mu \mathrm{m}$ (PM2.5) and ozone $\left(\mathrm{O}_{3}\right)$, downloadable from [69]. A remarkable source of global open data for monitoring the temporal evolution of air quality is available in satellite data. Table 3.4 lists satellites, sensors and relative spatial and temporal resolution.

TABLE 3.4

Satellites, sensors for air quality monitoring, spatial and temporal resolutions (source: [70])

\begin{tabular}{|c|c|c|c|}
\hline Satellite & Sensor & $\begin{array}{l}\text { Spatial } \\
\text { resolution }\end{array}$ & $\begin{array}{l}\text { Temporal } \\
\text { resolution }\end{array}$ \\
\hline Aqua & $\begin{array}{l}\text { Atmospheric Infrared Sounder (AIRS) } \\
\text { Level } 2 \text { and } 3 \text { products }\end{array}$ & $1^{\circ} x 1^{o}$ & $\begin{array}{l}\text { daily, 8-day, } \\
\text { monthly }\end{array}$ \\
\hline Terra and Aqua & 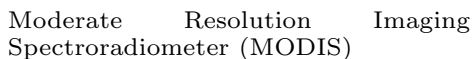 & $\begin{array}{l}250 \mathrm{~m}, 500 \mathrm{~m}, \\
1 \mathrm{~km}\end{array}$ & 1-2 days \\
\hline Terra & $\begin{array}{l}\text { Measurement of Pollution in the } \\
\text { Troposphere (MOPITT) }\end{array}$ & $1^{\circ} x 1^{o}$ & $\begin{array}{l}\text { daily, } \\
\text { monthly }\end{array}$ \\
\hline Aura & Ozone Monitoring Instrument (OMI) & $13 \mathrm{~km} \times 24 \mathrm{~km}$ & daily \\
\hline Suomi-NPP & $\begin{array}{l}\text { Ozone Mapping and Profiler Suite } \\
\text { (OMPS) }\end{array}$ & $50 \mathrm{~km} \times 50 \mathrm{~km}$ & $\begin{array}{l}101 \text { minutes, } \\
\text { daily }\end{array}$ \\
\hline Sentinel 5-P & $\begin{array}{ll}\text { TROPOspheric } & \text { Monitoring } \\
\text { Instrument (TROPOMI) } & \end{array}$ & $7 \mathrm{~km} \times 3.5 \mathrm{~km}$ & daily \\
\hline Suomi-NPP & $\begin{array}{l}\text { Visible Infrared Imaging Radiometer } \\
\text { Suite (VIIRS) }\end{array}$ & $375-750 \mathrm{~m}$ & 1-2 days \\
\hline
\end{tabular}

The most recent satellite of this family is represented by Sentinel 5P, launched in 2017 by the European Space Agency within the Copernicus Initiative. The onboard TROPOMI (TROPOspheric Monitoring Instrument) spectrometer allows the monitoring of ozone $\left(\mathrm{O}_{3}\right)$, methane $\left(\mathrm{CH}_{4}\right)$, formaldehyde ( $\mathrm{HCHO})$, aerosol, carbon monoxide $(\mathrm{CO})$, Nitrogen dioxide $\left(\mathrm{NO}_{2}\right)$ and Sulfur dioxide $\left(\mathrm{SO}_{2}\right)$. TROPOMI takes measurements every second covering an area of approximately $2600 \mathrm{~km}$ wide and $7 \mathrm{~km}$ long in a resolution of $7 \times 7 \mathrm{~km}$. Data can be freely downloaded upon registration. The first data were released in July 2018.

Using data from the Copernicus Sentinel-5P it was possible to analyse, for instance, the decline of air pollution, specifically $\mathrm{NO}_{2}$ concentrations, in some areas of the world as a consequence of 
the lockdown that was implemented to prevent the spread of the coronavirus. The maps in Figure 3.3 show the $\mathrm{NO}_{2}$ concentration over Italy before and during the lockdown.
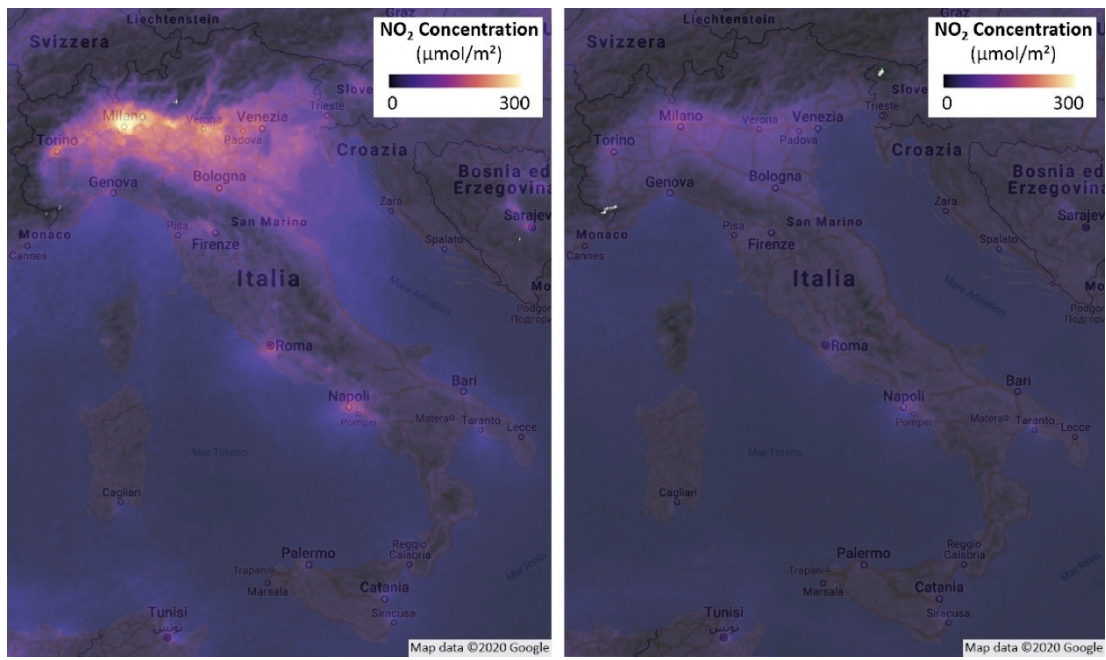

\section{FIGURE 3.3}

Concentration of $\mathrm{NO}_{2}$ over Italy before the lockdown (average value in January 2020) and during the lockdown (average value from 9 March to 9 April 2020)

Indoor air pollution is caused mainly by the use of solid fuels for cooking. While indoor air pollution has been on the decrease since the 1990s, $40 \%$ of the world population still does not have access to clean air cooking fuels. Death rates from air pollution are highest in low-income countries. A selection of indicators about indoor air pollution are available in visualizations (maps and graphs), and also for download from [71]. Indicators are provided at the country level, and were sourced from the World Bank and from the Global Health Data Exchange.

\subsubsection{Water Sources}

Referring to water and sanitation, indicators for the United Nations Sustainable Development Goal (SDG) 6 are available, but again, at country scale. Maps, charts and data can be found on the UN Water geoportal [72]. Figure 3.4 is an example, showing the proportion of the population in a country using safely managed sanitation services.

The local alternative, as seen before, is to consider the features related to water available in OpenStreetMap. By using overpass turbo (http://overpass-turbo.eu) and browsing to the area of interest, the simple query:

node

[amenity=drinking_water]

(\{\{bbox $\}\})$;

\section{Out;}

allows us, i.e. to obtain the map and data corresponding to points where drinkable water is available. The result of the query in a portion of Dar Es Salaam is shown in Figure 3.5. 


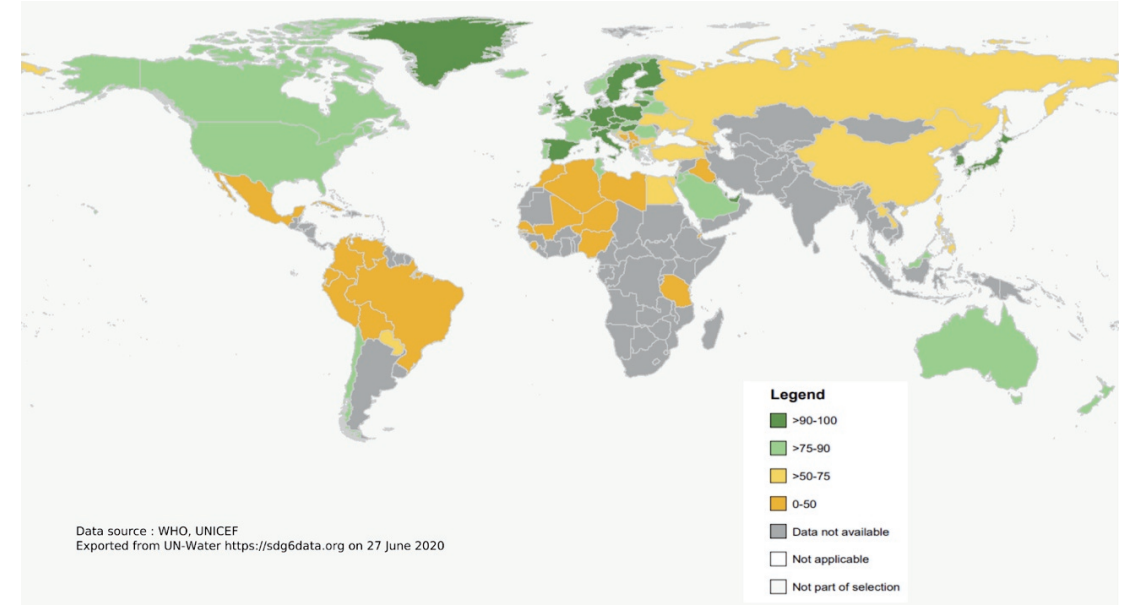

\section{FIGURE 3.4}

Proportion of population using safely managed sanitation services (Source: UN Water [73])

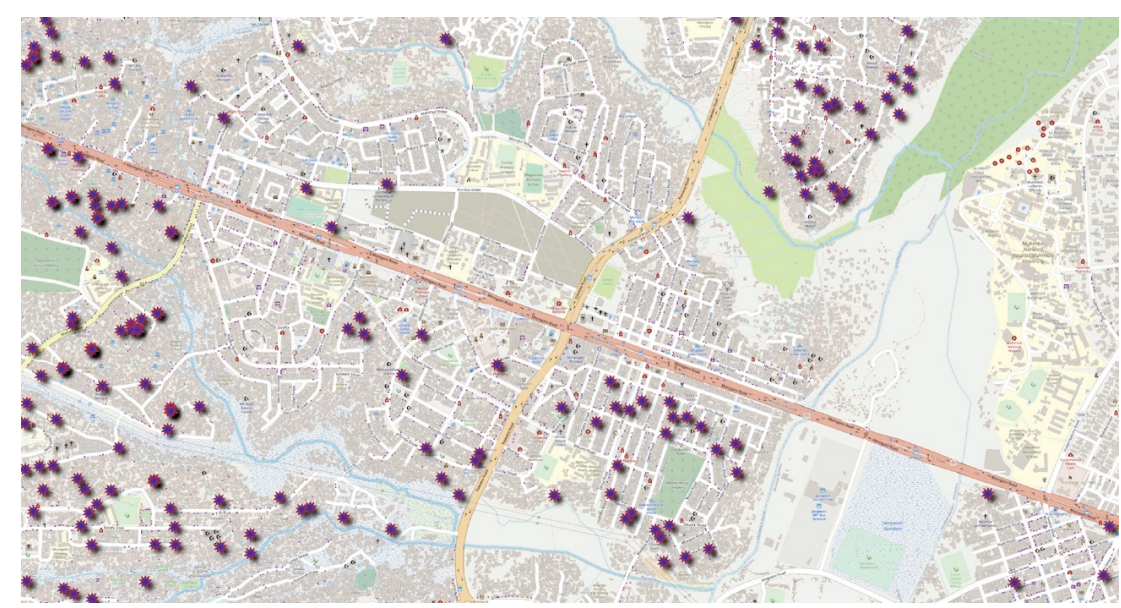

\section{FIGURE 3.5}

Drinking water locations in a portion of Dar Es Salaam (Source: OpenStreetMap contributors [74])

\subsubsection{Health Facilities}

General data about the health condition of the population (again at country level) can be found on the WHO website. The Global Health Observatory (GHO) [75] provides access to data and analyses for over 30 health themes ranging from health systems to disease-specific themes, as well as direct access to the full database. The same database archives data about the density of hospitals per 100,000 people (district/rural hospitals, health centres, health posts, provincial hospitals, specialized hospitals, hospitals as a whole), hospital beds (per 10,000 people), pharmacists, medical doctors, nurses and midwives (both absolute number, per 10,000 people, and density for 1,000 people). Some of this data can also be downloaded in cartographic format from the already mentioned website of the United Nations Statistics Division, in the "Healthcare Resources" section of the portal. 


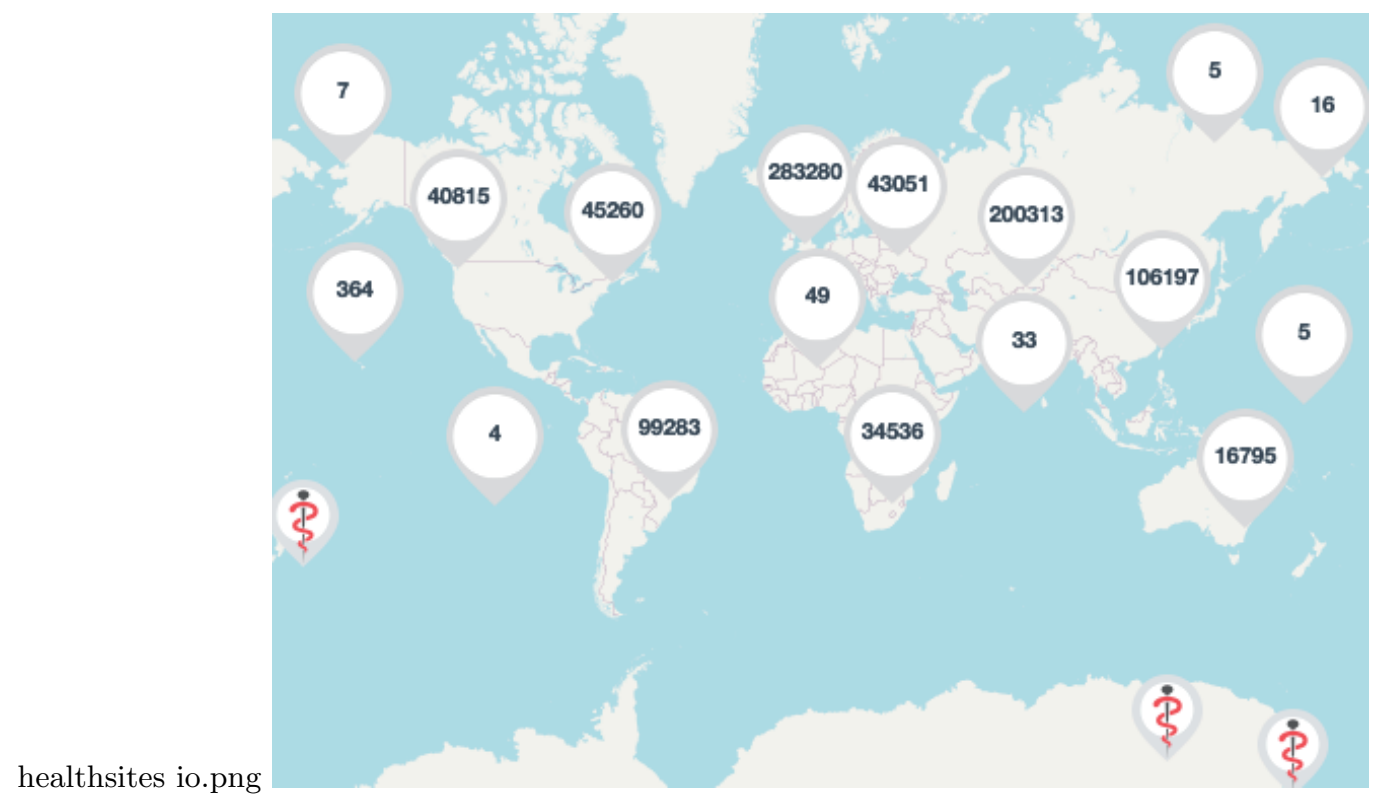

\section{FIGURE 3.6}

Location of health sites on 4 October 2020 (Source: HealthSites.io [76])

healthsites io graphs.png
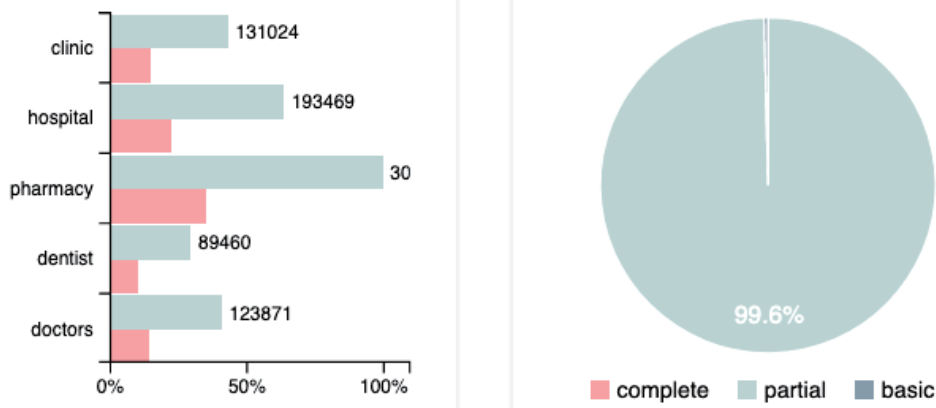

\section{FIGURE 3.7}

Number of heath sites per type (on the left) and completeness of attributes (on the right) on 4 October 2020 (Source: HealthSites.io [76])

Unfortunately, none of these datasets have local data. If one requires data at such granularity, the Global Healthsites Mapping Project [77], which is based on the OpenStreetMap data model, is a good starting point for finding locations and contact details of health facilities (clinics, doctors, hospitals, dentists, pharmacies, etc). It is a collaborative project and a long list of partners are contributing based on a citizen science or VGI (volunteered geographic information) approach. The Global Healthsites Mapping Project provides a domain specific view of OpenStreetMap data, focusing on the needs of those working with health facility data. The Heathsites.io platform [76] does not require users to be experts in the general OpenStreetMap data model and allows them to be more focused specifically on the health domain, even if the same data can be accessed from the general OpenStreetMap database and platform in various ways, e.g. with Overpass Turbo [78] or via the QuickOSM QGIS plugin [79]. Currently, 820,244 health sites are mapped (Figure 3.6), however, their descriptions are far from complete (Figure 3.7 ). 


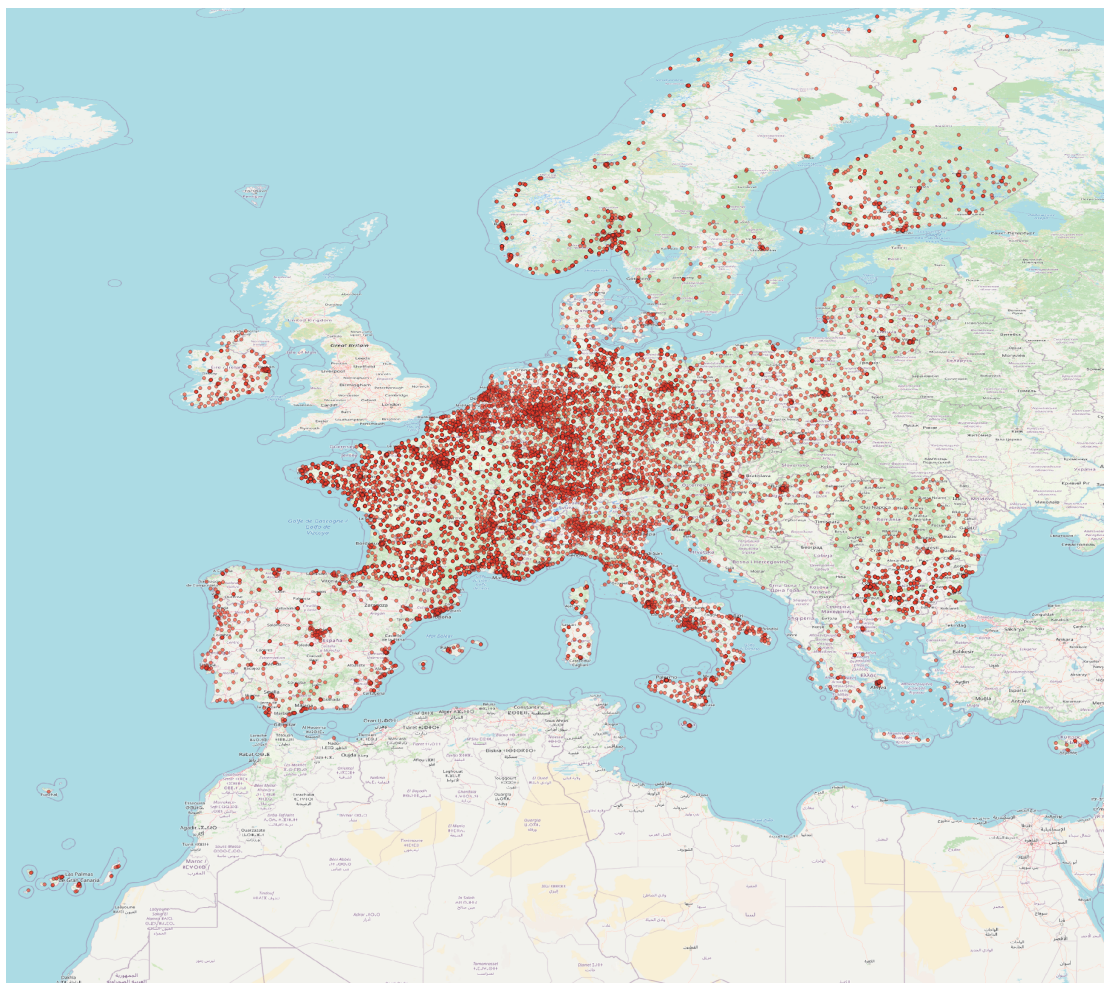

\section{FIGURE 3.8}

Locations of health sites in Europe on 4 October 2020 (Source: Eurostat [80])

Another interesting source of data, unfortunately only for Europe, is shared by Eurostat [80]. The dataset, which will be improved progressively, integrates the location of European healthcare services extracted from official national registers. By now it contains almost 15,000 features (Figure 3.8). When available, the capacity in terms of number of beds, rooms and practitioners and whether the healthcare site provides emergency medical services is archived. The dataset is not homogeneous neither in the level of detail nor in timeliness and update frequency. Nevertheless, it is well known that "reliable pan-European geospatial datasets for EU institutions are required to further develop GI capacities at EU level, and an important step in reducing inequalities across the EU" [81].

Global information about intensive care or ventilators is not available in any dataset. Similarly, location-based information about capacity of (and places for) collecting and treating medical and hazardous waste could not be found. To be precise, there is no data related to waste generally and again, the only source, however quite fragmented, is OpenStreetMap [82].

\subsection{Discussion and Conclusion}

Our study shows that global open datasets are available for many aspects of risk management before, during and after a pandemic. However, it is not always easy to find these datasets. Some of them can only be found via a (geo)portal, which often makes them inaccessible to web crawlers that search and index content for general purpose web search engines. Search engines specifically developed for datasets, such as Google's dataset search (https://datasetsearch . research.google.com), which crawls and indexes metadata about datasets in schema.org format, can improve the situation. Another challenge lies in finding the license terms and conditions for 
using open data. For some datasets that we discussed in this paper, the licensing information was readily available and simple to understand (e.g. standardized Creative Commons licenses). For others, we struggled to locate the licensing information or, when datasets are compiled from many different sources, different licenses may apply to different parts of the dataset (see for example, OpenAddresses.io).

The UN GGIM has identified a set of 14 global fundamental geospatial data themes, amongst others, in support of the 2030 Sustainable Development Agenda and its 17 Sustainable Development Goals (SDGs). These datasets are considered to be "the minimum primary sets of data that cannot be derived from other data sets, and that are required to spatially represent phenomena, objects, or themes important for the realisation of economic, social, and environmental benefits consistently" [83]. There is considerable overlap between nine of the UN GGIM fundamental geospatial datasets and the list of datasets that we identified as useful in the case of a global pandemic: Addresses, Buildings \& Settlements, Functional Areas (includes administrative areas), Geographical Names, Land Cover \& Land Use, Physical Infrastructure (includes schools and hospitals), Population Distribution, Transport Networks and Water. The list of fundamental geospatial data themes presents a foundation for global geospatial information management. As a next step, detailed regional specifications are being developed. Eventually, these will lead to improved geospatial information at the national level, which can then be integrated into global datasets.

The biggest concern with the global open datasets discussed in this chapter is that many of them are not available with sufficient granularity. Fine-grained data is particularly critical in the case of a global threat, such as the current pandemic. We live in a hyper-connected world and therefore, while taking into account local differences, many challenges need to be addressed at a global level. Therefore global analyses are required, based on data with much more detail than currently provided (e.g. mostly by country). There is a definite and urgent need to move towards providing high resolution global data.

Some government agencies are already moving in this direction, for example, ESA provides satellite imagery globally down to $10 \mathrm{~m}$ resolution (Sentinel 2) as open data. This makes global analyses possible that were previously unthinkable. Some private companies are also moving in this direction. Consider, for example, the case of Facebook which, with the Facebook Data for Good initiative, makes many dynamic data of interest for humanitarian purposes freely available to nonprofits and universities that have signed data license agreements.

Another fundamental move towards fine-grained data is exhibited by the many initiatives related to OpenStreetMap. OpenStreetMap has been confirmed as one of the most important geospatial data projects in the last 20 years. The quality of OpenStreetMap data is often the subject to criticism. However, the wider OpenStreetMap community, which includes other communities, such as HOT, Missing Maps, Healthsites, Geochicas, etc., has equipped itself with tools and procedures that allow a solid first validation of the data. For example, during the pandemic, HOT created at least 199 projects covering approximately 124,000 $\mathrm{km}^{2}$, many of which had been mapped and validated by the time of writing this chapter. It is in the communities' own best interest to provide the best possible data, not only because they will use their own data, but also because there is awareness among volunteers that the data will be used for humanitarian purposes and therefore the better it is, the more effective it can be. Many scientific publications have examined the quality of OpenStreetMap data in various case studies. The results are generally comforting because where OpenStreetMap communities are more developed and mature, the comparison with authoritative data [84], [85], [86] is very favourable. Where OpenStreetMap data are scarce, it is often not possible to make comparisons with reference data because these data simply do not exist or are not available [46].

Academics have approached OpenStreetMap with slowness, gathering some momentum in recent years, not only on aspects of general interest, that is the collaborative collection of data, but also the educational perspective of such an experience. In 2014, the academic community developed YouthMappers [88] to explicitly bring together and nurture the student communities and their faculty that operate within and together with the broader set of OpenStreetMap communities around youth-based identities. Founded by faculty from Texas Tech University, the George Washington University, and West Virginia University, with support from the US Agency for International Development's GeoCenter, and now administered by Arizona State University, 


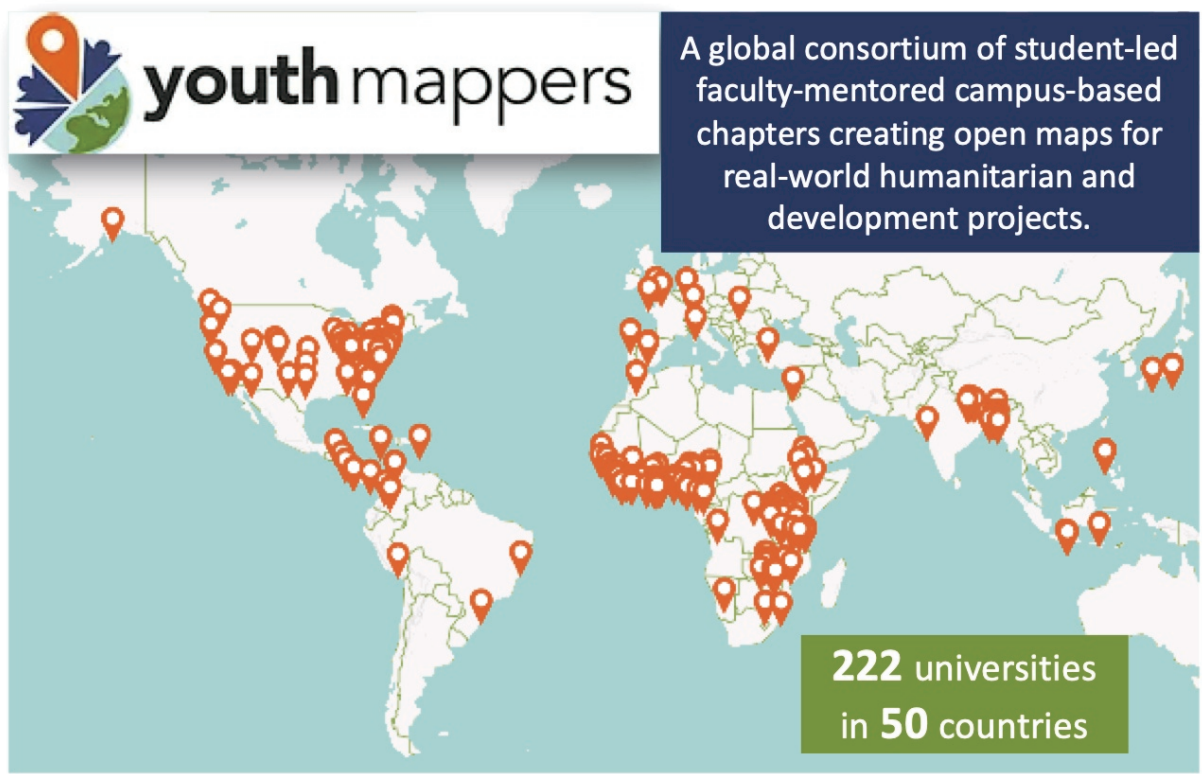

\section{FIGURE 3.9}

Locations of YouthMappers Chapters in October 2020 (Source: YouthMappers [87])

YouthMappers organize as chapters on university campuses, run by student leadership under the guidance of university professor mentors. By October 2020, the network had grown (Figure 3.9) to 222 campus chapters in 50 countries, linking more than 5,000 OpenStreetMap students volunteers [87]. YouthMappers' motto is "We don't just build maps. We build mappers", emphasizing the importance of mapping the world in order to get to know it better. This experience should, in the opinion of the authors of the chapter, become the heritage of all schools and universities because it would be an enrichment of global knowledge of the world and, at the same time, an enrichment of the skills of young people. Governments should encourage and support these initiatives, taking the advantage of having more detailed maps and more geographically aware young citizens. University networks, such as the UN GGIM Academic Network, could become sounding boards for the initiative itself and contribute both to its dissemination and to the design and development of procedures for data assessment, which would therefore become the heritage of all humanity.

\section{Annex: List of datasets}

The list of datasets is available at https://docs . google.com/spreadsheets/d/19amm6CbDOTOPObA8xcZ8itdCMaOPXSu30qUVuDQr4s/edit\#gid=0.

\section{References}

[1] World Health Organization. Advice on the use of masks in the context of COVID-19. Interim guidance WHO/2019-nCov/IPC_Masks/2020.4, World Health Organization, June 2020. URL https://apps.who.int/ iris/handle/10665/332293. 
[2] United Nations, Department of Economic and Social Affairs, Statistics. UN COVID-19 Data Hub, 2020. URL https://covid-19-data.unstatshub.org/. Library Catalog: covid-19-data.unstatshub.org.

[3] Centers for Disease Control and Prevention. Zoonotic Diseases, July 2017. URL https://www.cdc.gov/ onehealth/basics/zoonotic-diseases.html. Library Catalog: www.cdc.gov.

[4] UN-GGIM Working Group on Geospatial Information and Services for Disasters (WG-GISD). Strategic Framework on Geospatial Information and Services for Disasters. Technical report, United Nations Committee of Experts on Global Geospatial Information Management, August 2017. URL http://ggim.un.org/UN-GGIMpublications/.

[5] Codrina Maria Ilie, Maria Antonia Brovelli, and Serena Coetzee. Monitoring SDG 9 with global open data and open software: A case study from rural Tanzania. ISPRS - International Archives of the Photogrammetry, Remote Sensing and Spatial Information Sciences, XLII-2/W13:1551-1558, June 2019. ISSN $2194-9034$. doi: 10.5194/isprs-archives-XLII-2-W13-1551-2019. URL https://www.int-arch-photogramm-remote-sensspatial-inf-sci.net/XLII-2-W13/1551/2019/.

[6] Open Knowledge Foundation. What is open?, 2020. URL https://okfn.org. Library Catalog: okfn.org.

[7] Maria Antonia Brovelli, Codrina Maria Ilie, and Serena Coetzee. Openness and Community Geospatial Science for Monitoring SDGs: An Example From Tanzania. In Abbas Rajabifard, editor, Sustainable Development Goals Connectivity Dilemma: Land and Geospatial Information for Urban and Rural Resilience, pages 313-324. CRC Press, Boca Raton, 1 edition, August 2019. ISBN 978-0-429-29062-6. doi: 10.1201/9780429290626. URL https://www.taylorfrancis.com/books/9781000690682.

[8] Serena Coetzee, Ivana Ivánová, Helena Mitasova, and Maria Brovelli. Open Geospatial Software and Data: A Review of the Current State and A Perspective into the Future. ISPRS International Journal of Geo-Information, 9(2):90, February 2020. ISSN 2220-9964. doi: 10.3390/ijgi9020090. URL https: //www.mdpi.com/2220-9964/9/2/90.

[9] United Nations Office for Disaster Risk Reduction. Sendai Framework for Disaster Risk Reduction 2015 2030. Technical report, United Nations, New York, 2015. URL https://www.undrr.org/publication/sendaiframework-disaster-risk-reduction-2015-2030.

[10] Organisation for Economic Co-operation and Development (OECD). Environmental health and strengthening resilience to pandemics. Technical report, Organisation for Economic Co-operation and Development (OECD), 2020. URL https://read.oecd-ilibrary.org/view/?ref=129_129937-jm4ul2jun9\&title=Environmental-healthand-strengthening-resilience-to-pandemics.

[11] World Health Organization. Recommendations to Member States to improve hand hygiene practices to help prevent the transmission of the COVID-19 virus. Interim guidance WHO/2019-nCov/Hand_Hygiene_Stations/2020.1, World Health Organization, April 2020. URL https://www . who.int/publications/i/item/recommendations-to-member-states-to-improve-hand-hygienepractices-to-help-prevent-the-transmission-of-the-covid-19-virus.

[12] United Nations, Department of Economic and Social Affairs, Sustainable Development. Goal 6 | Department of Economic and Social Affairs, 2020. URL https://sdgs.un.org/goals/goal6.

[13] Markus Amann, Mike Holland, Rob Maas, Bert Saveyn, and Toon Vandyck. Costs, benefits and economic impacts of the EU Clean Air Strategy and their implications on innovation and competitiveness. Technical report, IIASA, 2017. URL http://gains.iiasa.ac.at.

[14] World Health Organization. Critical preparedness, readiness and response actions for COVID-19. Interim guidance WHO/COVID-19/Community_Actions/2020.4, World Health Organization, June 2020. URL https: //www . who.int/publications/i/item/critical-preparedness-readiness-and-response-actions-for-covid-19.

[15] CSSEGISandData. CSSEGISandData/COVID-19, July 2020. URL https://github.com/CSSEGISandData/ COVID-19. original-date: 2020-02-04T22:03:53Z.

[16] European Centre for Disease Prevention and Control (ECDC). Download today's data on the geographic distribution of COVID-19 cases worldwide, July 2020. URL https://www.ecdc.europa.eu/ en/publications-data/download-todays-data-geographic-distribution-covid-19-cases-worldwide. Library Catalog: www.ecdc.europa.eu.

[17] Max Roser, Hannah Ritchie, Esteban Ortiz-Ospina, and Joe Hasell. Coronavirus Pandemic (COVID-19). Our World in Data, March 2020. URL https://ourworldindata.org/coronavirus.

[18] Hannah Ritchie. Google Mobility Trends: How has the pandemic changed the movement of people around the world?, June 2020. URL https://ourworldindata.org/covid-mobility-trends. Library Catalog: ourworldindata.org.

[19] Mordechai Haklay. How Good is Volunteered Geographical Information? A Comparative Study of OpenStreetMap and Ordnance Survey Datasets. Design, 37(4):682-703, 2010. doi: 10.1068/b35097. https://doi.org/10.1068/b35097.

Environment and Planning B: Planning and URL https://doi.org/10.1068/b35097. _eprint: 
[20] Humanitarian OpenStreetMap Team (HOT). HOT COVID-19 RESPONSE, 2020. URL https://www.hotosm. org/projects/hot-covid-19-response/.

[21] The Awareness Company. COVID-19 Awareness, 2020. URL https://health.hydra.africa/\#/. Library Catalog: health.hydra.africa.

[22] HealthMap. Novel Coronavirus (COVID-19), 2020. URL https://www.healthmap.org/covid-19/.

[23] RCMRD. RCMRD Covid-19 Open Data Hub, 2020. URL http://covid19.rcmrd.org/. Library Catalog: covid19.rcmrd.org.

[24] NSF Spatiotemporal Innovation Center,. COVID-19 Spatiotemporal Rapid Response Gateway, 2020. URL https://covid-19.stcenter.net/index.php/covid19-livemap/.

[25] NAVER Corporation. Coronamap site, 2020. URL https://coronamap.site/. Library Catalog: coronamap.site.

[26] geo-spatial.org. Coronavirus COVID-19 România, 2020. URL https://covid19.geo-spatial.org/.

[27] OpenStreetMap Wiki Contributors. Wikimapia, June 2019. URL https://wiki.openstreetmap.org/wiki/ Wikimapia.

[28] Natural Earth. Natural Earth, 2020. URL https://www.naturalearthdata.com/. Library Catalog: www.naturalearthdata.com.

[29] Earth Observing System. 7 Top Free Satellite Imagery Sources in 2019, 2020. URL https://eos.com/blog/7top-free-satellite-imagery-sources-in-2019/.

[30] HOT partners and community. OpenAerialMap, 2020. URL http://openaerialmap.org/. Library Catalog: openaerialmap.org.

[31] United States Board on Geographic Names. NGA GEOnet Names Server (GNS), 2020. URL https:// geonames.nga.mil/gns/html/index.html.

[32] US Board on Geographic Names. Domestic Names, 2020. URL https://www.usgs.gov/core-science-systems/ ngp/board-on-geographic-names.

[33] foursquare. Quattroshapes by foursquare, 2020. URL http://quattroshapes.com/.

[34] World Bank. World Bank Official Boundaries, 2020. URL https://datacatalog.worldbank.org/dataset/worldbank-official-boundaries.

[35] United Nations Office for the Coordination of Humanitarian Affairs (OCHA). Humanitarian Data Exchange, 2020. URL https://data.humdata.org/. Library Catalog: data.humdata.org.

[36] GADM. GADM website, 2020. URL https://www.gadm.org/.

[37] Wikipedia contributors. GADM, March 2019. URL https://en.wikipedia.org/w/index.php?title=GADM\&oldid= 888438996. Page Version ID: 888438996.

[38] Wikipedia contributors. Refugee camp, June 2020. URL https://en.wikipedia.org/w/index.php?title= Refugee_camp\&oldid=965048407. Page Version ID: 965048407.

[39] UNHCR, The UN Refugee Agency. Operational Portal - Refugee Situations, 2020. URL https://data2.unhcr. org/en/situations.

[40] OpenStreetMap Wiki Contributors. Points of interest, April 2020. URL https://wiki.openstreetmap.org/ wiki/Points_of_interest.

[41] Wikimapia. Wikimapia - Let's describe the whole world!, 2020. URL http://wikimapia.org/\#lang=en\&lat=$29.000000 \&$ Ion $=24.000000 \& z=12 \& m=w$.

[42] Center for International Earth Science Information Network - CIESIN - Columbia University, and Information Technology Outreach Services - ITOS - University of Georgia. Global Roads Open Access Data Set, Version 1 (gROADSv1), 2013. URL https://sedac.ciesin.columbia.edu/data/set/groads-global-roads-open-accessv1.

[43] OpenStreetMap Wiki Contributors. Map Features, July 2019. URL https://wiki.openstreetmap.org/wiki/ Map_Features.

[44] Maria Brovelli, Marco Minghini, Monia Molinari, and Peter Mooney. A FOSS4G-based procedure to compare OpenStreetMap and authoritative road network datasets. In Geomatics Workbooks No 12, Como, Italy, 2015.

[45] Maria Brovelli, Marco Minghini, Monia Molinari, and Peter Mooney. Towards an Automated Comparison of OpenStreetMap with Authoritative Road Datasets. Transactions in GIS, 21(2):191-206, 2017. doi: 10.1111/ tgis.12182. 
[46] Stefan Jovanovic, Dina Jovanovic, Gorica Bratic, and Maria Antonia Brovelli. Analysis of free road data in Tanzania, Ugana and Kenya using free and open source software. ISPRS - International Archives of the Photogrammetry, Remote Sensing and Spatial Information Sciences, XLII-2/W13:1567-1572, 2019. doi: 10.5194/isprs-archives-XLII-2-W13-1567-2019. URL https://www.int-arch-photogramm-remote-sensspatial-inf-sci.net/XLII-2-W13/1567/2019/.

[47] Google LLC. COVID-19 Community Mobility Report, 2020. URL https://www.google.com/covid19/mobility? hl=en. Library Catalog: www.google.com.

[48] Facebook. Facebook Data for Good, 2020. URL https://dataforgood.fb.com/. Library Catalog: dataforgood.fb.com.

[49] Joe Schwartz. Bing Maps Tile System - Bing Maps, 2018. URL https://docs.microsoft.com/en-us/bingmaps/ articles/bing-maps-tile-system. Library Catalog: docs.microsoft.com.

[50] Serena Coetzee, Martijn Odijk, Bastiaan van Loenen, Janette Storm, and Jantien Stoter. Stakeholder analysis of the governance framework of a national SDI dataset - whose needs are met in the buildings and address register of the Netherlands? International Journal of Digital Earth, 13(3):355-373, March 2020. ISSN 1753-8947, 1753-8955. doi: 10.1080/17538947.2018.1520930. URL https://www.tandfonline.com/doi/full/10. $1080 / 17538947.2018 .1520930$.

[51] Universal Postal Union. About addressing, 2020. URL http://www.upu.int/en/activities/addressing/aboutaddressing.html.

[52] OpenAddresses.io. About openaddresses.io, 2020. URL https://openaddresses.io/.

[53] Serena Coetzee and Antony K Cooper. What is an address in South Africa? South African Journal of Science, 103:10, 2007.

[54] International Organization for Standardization (ISO). ISO 19160-1:2015, Addressing — Part 1: Conceptual model. Technical report, International Organization for Standardization (ISO), Geneva, 2015. URL https: //www.iso.org/obp/ui/\#iso:std:iso: 19160:-1:ed-1:v1:en.

[55] OpenStreetMap Contributors. OpenStreetMap Taginfo, 2020. URL https://taginfo.openstreetmap.org/.

[56] OpenStreetMap Wiki Contributors. Address Improvement, May 2019. URL https://wiki.openstreetmap.org/ wiki/Address_Improvement.

[57] World Bank. World Bank Open Data, 2020. URL https://data.worldbank.org/.

[58] Organisation for Economic Co-operation and Development (OECD). OECD Statistics, 2020. URL https: //stats. oecd.org/\#.

[59] World Bank. Population ages 0-14 (\% of total population), 2020. URL https://data.worldbank.org/indicator/ SP.POP.0014.TO.ZS.

[60] World Bank. Population ages 15-64 (\% of total population), 2020. URL https://data.worldbank.org/ indicator/SP.POP.1564.TO.ZS.

[61] World Bank. Population ages 65 and above (\% of total population), 2020. URL https://data.worldbank.org/ indicator/SP.POP.65UP.TO.ZS.

[62] United Nations, Department of Economic and Social Affairs, Population Division. World population prospects 2019. Volume I: Comprehensive Tables (ST/ESA/SER.A/426). United Nations, New York, 2019. ISBN 978-92-1-148327-7. URL https://population.un.org/wpp/Publications/Files/WPP2019_VolumeI_Comprehensive-Tables.pdf. OCLC: 1130546520.

[63] United Nations, Department of Economic and Social Affairs, Population Division. World Population Prospects 2019. Volume II: Demographic Profiles (ST/ESA/SER.A/427). United Nations, New York, 2019. ISBN 978-92-1-004643-5. doi: 10.18356/7707d011-en. URL https://www.un-ilibrary.org/populationand-demography/world-population-prospects-2019-volume-ii-demographic-profiles_7707d011-en.

[64] Center For International Earth Science Information Network-CIESIN-Columbia University. Gridded Population of the World, Version 4 (GPWv4): Population Density, Revision 11, 2018. URL https://sedac. ciesin.columbia.edu/data/set/gpw-v4-population-density-rev11. type: dataset.

[65] United Nations, Department of Economic and Social Affairs, Population Division. World Population Prospect - The 2015 revision. Key findings and advance tables. Technical Report ESA/P/WP.241, United Nations, New York, 2015. URL https://www.un.org/en/development/desa/publications/world-population-prospects2015-revision.html.

[66] Facebook Connectivity Lab and Center for International Earth Science Information Network - CIESIN - Columbia University. High Resolution Settlement Layer (HRSL). Source imagery for HRSL (C) 2016 DigitalGlobe., 2016. URL https://www.ciesin.columbia.edu/data/hrsl/\#data.

[67] WorldPop. Open Spatial Demographic Data and Research, 2020. URL https://www. worldpop.org/. 
[68] Andrew J. Tatem. WorldPop, open data for spatial demography. Scientific Data, 4(1):1-4, December 2017. ISSN 2052-4463. doi: 10.1038/sdata.2017.4. URL http://www.nature.com/articles/sdata20174.

[69] Hannah Ritchie and Max Roser. Outdoor Air Pollution. Our World in Data, November 2019. URL https: //ourworldindata.org/outdoor-air-pollution.

[70] NASA EarthData. Health and Air Quality Data Pathfinder | Earthdata, May 2020. URL https://earthdata. nasa.gov/learn/pathfinders/health-and-air-quality-data-pathfinder.

[71] Hannah Ritchie and Max Roser. Indoor Air Pollution. Our World in Data, November 2019. URL https: //ourworldindata.org/indoor-air-pollution.

[72] UN-Water. UN-Water SDG 6 Data Portal, 2020. URL https://sdg6data.org/.

[73] UN Water. Un water maps, 2020. URL https://sdg6data.org/maps.

[74] OpenStreetMap Contributors. OpenStreetMap, 2020. URL https://openstreetmap.org/.

[75] World Health Organization. The Global Health Observatory, 2020. URL https://www. who.int/data/gho/data/ indicators.

[76] healthsites.io. About healthsites.io, 2020. URL https://healthsites.io/.

[77] OpenStreetMap Wiki Contributors. Global Healthsites Mapping Project, 2020. URL https://wiki. openstreetmap.org/w/index.php?title=Global_Healthsites_Mapping_Project\&oldid=1971053.

[78] OpenStreetMap Wiki Contributors. Overpass turbo, February 2020. URL https://wiki.openstreetmap.org/ wiki/Overpass_turbo.

[79] QGIS project. 10.2. Lesson: Useful QGIS Plugins - QGIS Documentation documentation, 2020. URL https://docs.qgis.org/3.10/en/docs/training_manual/qgis_plugins/plugin_examples.html.

[80] Eurostat. Healthcare services, 2020. URL https://ec.europa.eu/eurostat/web/gisco/geodata/reference-data/ healthcare-services.

[81] Eurostat. Healthcare services in Europe, 2020. URL https://gisco-services.ec.europa.eu/pub/healthcare/ metadata.pdf.

[82] OpenStreetMap Wiki Contributors. Waste Processing, July 2020. URL https://wiki.openstreetmap.org/ wiki/Waste_Processing.

[83] United Nations Committee of Experts on Global Geospatial Information Management. The Global Fundamental Geospatial Data Themes, 2019. URL https://ggim.un.org/documents/Fundamental\%20Data\% 20Publication.pdf.

[84] Maria Antonia Brovelli, MArco Minghini, and Monia Elisa Molinari. An automated GRASS-based procedure to assss the geometrical accuracy of the OpenStreetMap Paris road network. ISPRS - International Archives of the Photogrammetry, Remote Sensing and Spatial Information Sciences, XLI-B7:919-925, 2016. doi: 10.5194/isprs-archives-XLI-B7-919-2016. URL https://www.int-arch-photogramm-remote-sens-spatial-infsci.net/XLI-B7/919/2016/.

[85] M. A. Brovelli, M. Minghini, M. E. Molinari, and G. Zamboni. Positional accuracy assessment of the OpenStreetMap Buildings layer through automatic homologous pairs detection: the method and a case study. ISPRS - International Archives of the Photogrammetry, Remote Sensing and Spatial Information Sciences, XLI-B2:615-620, 2016. doi: 10.5194/isprs-archives-XLI-B2-615-2016. URL https://www.int-archphotogramm-remote-sens-spatial-inf-sci.net/XLI-B2/615/2016/.

[86] Maria Brovelli and Giorgio Zamboni. A New Method for the Assessment of Spatial Accuracy and Completeness of OpenStreetMap Building Footprints. ISPRS International Journal of Geo-Information, 7(8):289, July 2018. ISSN 2220-9964. doi: 10.3390/ijgi7080289. URL http://www.mdpi.com/2220-9964/7/8/289.

[87] YouthMappers. YouthMappers Chapter Profiles, 2020. URL https://www . youthmappers.org/chapters. Library Catalog: www.youthmappers.org.

[88] Patricia Solís, Brent McCusker, Nwasinachi Menkiti, Nuala Cowan, and Chad Blevins. Engaging global youth in participatory spatial data creation for the UN sustainable development goals: The case of open mapping for malaria prevention. Applied Geography, 98:143-155, 2018. doi: 10.1016/j.apgeog.2018.07.013. 
$\Longrightarrow$ Taylor \& Francis Taylor \& Francis Group

http://taylorandfrancis.com 